Article

\title{
Factors Influencing the Capillary Water Absorption Characteristics of Concrete and Their Relationship to Pore Structure
}

\author{
Yue Wang ${ }^{1, *}$, Liangshun $\mathrm{Li}^{1}{ }^{1}$, Mingzhe An ${ }^{1}$, Yifan Sun ${ }^{1}$, Ziruo Yu ${ }^{1}$ and Hanfeng Huang ${ }^{1,2}$ \\ 1 School of Civil Engineering, Beijing Jiaotong University, Haidian District, Beijing 100044, China; \\ 20121067@bjtu.edu.cn (L.L.); mzhan@bjtu.edu.cn (M.A.); BJ18811233651@163.com (Y.S.); \\ zryu@bjtu.edu.cn (Z.Y.); $15115310 @ b j t u . e d u . c n(H . H$. \\ 2 Beijing Urban Construction Group Co., Ltd., Chaoyang District, Beijing 100020, China \\ * Correspondence: yue.wang@bjtu.edu.cn; Tel.: +86-1051688237
}

check for

updates

Citation: Wang, Y.; Li, L.; An, M.; Sun, Y.; Yu, Z.; Huang, H. Factors Influencing the Capillary Water Absorption Characteristics of Concrete and Their Relationship to Pore Structure. Appl. Sci. 2022, 12, 2211. https://doi.org/10.3390/ app12042211

Academic Editor: Roman

Wan-Wendner

Received: 30 January 2022

Accepted: 18 February 2022

Published: 20 February 2022

Publisher's Note: MDPI stays neutral with regard to jurisdictional claims in published maps and institutional affiliations.

Copyright: (C) 2022 by the authors. Licensee MDPI, Basel, Switzerland. This article is an open access article distributed under the terms and conditions of the Creative Commons Attribution (CC BY) license (https:// creativecommons.org/licenses/by/ $4.0 /)$.

\begin{abstract}
The capillary absorption capacity exerts an important effect on the durability of cementbased materials and is closely related to the pore structure. In this study, a variety of cement-based specimens were examined. The capillary water absorption and pore structure of the samples were determined using a gravimetric method and mercury intrusion porosimetry (MIP), respectively. The capillary water absorption coefficients for different water-binder ratios, diverse types and dosages of mineral admixtures, and various preloads were measured. The experimental results were analyzed and compared with data available in the current literature. The test results showed that the capillary water absorption performance of cement-based materials increased with an increasing water-binder ratio, first decreased and then increased with an increasing fly ash dosage, decreased with an increasing mineral power dosage, and decreased when the preload was less than a critical value and increased rapidly when the preload was greater than the critical value. The relationship between the capillary absorption coefficient and porosity was nearly linear. Water absorption by cement-based materials mainly correlated with pore diameters in the range of 10 1000 nm. The capillary water absorption coefficient increased continuously with the increase of pore fractal dimension.
\end{abstract}

Keywords: capillary water absorption; water-binder ratio; mineral admixtures; preload level; pore structure

\section{Introduction}

Currently, with the development of national infrastructure, cement-based materials are being used in increasingly harsh environments that impose increasing demands on their durability. Water is the most important fluid that may penetrate concrete [1,2], as its transport in the pore network plays a key role in most types of ion erosion behaviour [3]. Water transport is the main cause of concrete deterioration [4,5]. During the deterioration process of cement-based materials, water usually participates in various forms of deterioration processes. Moisture is not only a direct participant in the physical deterioration of cement-based materials, but it is also an indirect participant in chemical deterioration. Water becomes the carrier of corrosive ions [6], and water permeability has been reported to predict concrete durability $[7,8]$. The capillary absorption test is the most common method used to study water transport within concrete, and the capillary absorption coefficient was selected to characterize the rate of water entry into the interior of porous materials [9]. Therefore, studies of the water transport of cement-based materials by performing capillary water absorption tests are very important to evaluate the performance of cement-based materials, predict their service life, and improve the level of durability design [10]. The capillary water absorption characteristics are closely related to the pore structure [11], and Oltulu et al. [12] found a statistically significant relationship between the pore size distribution obtained using mercury intrusion porosimetry (MIP) and Brunauer-Emmett-Teller 
(BET) tests and the capillary water absorption coefficient of mortar. Mobili et al. [13] and Gao et al. [14] concluded that with the increasing use of recycled aggregates and external loading, the porosity of cement-based materials increases, and the capillary water absorption coefficient increases accordingly. Luo et al. [15] and Yang et al. [16] showed that the porosity and pore size distribution of concrete are inextricably linked to the water transfer rate when rehydration occurs in concrete with a low water-cement ratio and described the effect of hydration products that fill the pore structure; they reported that the addition of fly ash reduced the water transfer rate of the slurry. Shi et al. [17] and Huang [18] applied the fractal dimension to study the pore structure of concrete, and their results showed that the smaller the fractal dimension, the smaller the corresponding porosity of the specimen, and the permeability of specimens was related to their porosity, fractal dimension, and average pore size.

Several characteristics of cement-based materials, such as the water-binder ratio, mineral admixture dosage, curing conditions, and external preload level, affect the pore structure [19] and capillary water absorption characteristics [20]. Wong et al. [21] found that the capillary water absorption coefficient of cement-based materials is related to the thickness of the specimen, and thinner specimens have higher permeability. Zeng et al. [22] found that the addition of an air-entraining agent introduced many small air bubbles, which reduced the capillary water absorption coefficient. According to He et al. [23] steam curing damages cement-based materials, which increases the capillary water absorption coefficient, and water curing of damaged specimens reduces the capillary water absorption coefficient. As shown in the study by Zhang et al. [24] the capillary absorption coefficient of ordinary concrete increases due to the increase in the number of capillary pores under the effect of freeze-thaw cycles, and this change is lower for concrete with a low waterbinder ratio than concrete with a high water-binder ratio under the same conditions. Ren et al. [25] reported that the water sensitivity of C-S-H gel was the main explanation for the two-stage capillary water absorption effect in cement-based materials. Baricevic et al. [26] proposed that the addition of fibers to concrete would block capillary pores, reduce pore connectivity, and decrease the capillary water absorption coefficient. The capillary water absorption characteristics of cement-based materials are potentially affected by many factors, and the clarification of the relationship between different factors and capillary water absorption characteristics may help researchers enhance the impermeability and durability of cement-based materials. This paper describes the results of capillary water absorption tests and previous research and investigates the capillary water absorption coefficients of cement-based materials with different water-binder ratios, types and dosages of mineral admixtures, preloads, and different porosities. The capillary water absorption coefficients of cement-based material in the presence of different influencing factors were analyzed by combining the data from the existing literature and experimental data. The relationship between the pore content and the capillary absorption coefficient in cement-based materials with different pore sizes was obtained using MIP and a gravimetric method [27], and the relationship between the pore content and the capillary absorption coefficient in materials with different pore sizes was further clarified based on the relationship between the porosity and the capillary absorption coefficient and the pore structure in the pore size range with the greatest effect on the capillary absorption coefficient of cement-based materials. Methods to reduce the capillary water absorption coefficient of cement-based materials were clarified by controlling the corresponding influencing factors to enhance the impermeability and durability of cement-based materials.

\section{Materials and Methods}

\subsection{Materials}

In this study, the raw materials were 42.5 ordinary Portland cement (P.O 42.5) complying with Chinese Standard GB175-2007, with a strength grade of $42.5 \mathrm{MPa}$ [28], and first-grade fly ash and silica fume. The chemical compositions and physical properties of these materials are shown in Table 1. Additionally, fine steel fibers (13 $\mathrm{mm}$ in length and 
$0.22 \mathrm{~mm}$ in diameter) with tensile strength of $2800 \mathrm{MPa}$ were used. The fine aggregate was river sand with a fineness modulus of 2.6. Two coarse aggregate gravels with particle size ranges of $5 \sim 10 \mathrm{~mm}$ and $10 \sim 25 \mathrm{~mm}$ were blended in proportions of $40 \%$ and $60 \%$, respectively. In addition, a polycarboxylate superplasticizer with a $30 \%$ water-reducing rate and $40 \%$ total solid content was used.

Table 1. Chemical compositions of cement, silica fume, and fly ash.

\begin{tabular}{|c|c|c|c|c|c|c|c|c|c|}
\hline Item & $\mathrm{MgO}$ & $\mathrm{Al}_{2} \mathrm{O}_{3}$ & $\mathrm{SiO}_{2}$ & $\mathrm{SO}_{3}$ & $\mathrm{CaO}$ & $\mathrm{Fe}_{2} \mathrm{O}_{3}$ & $\mathrm{Na}_{2} \mathrm{O}+\mathrm{K}_{2} \mathrm{O}$ & $\mathrm{Cl}^{-}$ & $\mathrm{f}-\mathrm{CaO}$ \\
\hline Cement & 2.32 & 4.44 & 21.65 & 3.14 & 62.80 & 2.78 & & 0.007 & 0.79 \\
\hline Fly ash & 1.04 & 34.95 & 53.07 & 2.59 & 2.80 & 2.86 & 2.69 & & \\
\hline $\begin{array}{l}\text { Silica } \\
\text { fume }\end{array}$ & 1.31 & 0.97 & 90.4 & 0.27 & 0.36 & 1.81 & 1.00 & & \\
\hline
\end{tabular}

\subsection{Mix Proportions}

The mix proportions of the concrete are shown in Table 2. Cubes with dimensions of $100 \mathrm{~mm} \times 100 \mathrm{~mm} \times 100 \mathrm{~mm}$ were produced. The fresh concrete was compacted in plastic molds and allowed to harden in the laboratory. After $24 \mathrm{~h}$, the cubes were removed from the molds and placed in a curing room with a controlled temperature of $\mathrm{T}=20 \pm 2{ }^{\circ} \mathrm{C}$ and a relative humidity $(\mathrm{RH})>95 \%$. After $28 \mathrm{~d}$ of curing, the cubes were removed from the curing room and used for the capillary water absorption test. In Table 2, PC, PCF, PCS, NC, HPC, and UHPC represent cement paste, cement paste with fly ash, cement paste with silica fume, normal concrete, concrete with fly ash, and ultrahigh performance concrete, respectively.

Table 2. Mix proportions and compressive strength of concrete.

\begin{tabular}{|c|c|c|c|c|c|c|c|c|c|c|c|}
\hline \multirow[b]{2}{*}{ Code } & \multirow{2}{*}{$\begin{array}{l}\text { Water/ } \\
\text { Binder } \\
\text { Ratio }\end{array}$} & \multicolumn{8}{|c|}{ Mix Proportion $\left(\mathrm{kg} / \mathrm{m}^{3}\right)$} & \multirow{2}{*}{$\begin{array}{l}\text { Steel Fibre } \\
\text { Volume } V f \\
(\%)\end{array}$} & \multirow{2}{*}{$\begin{array}{l}\text { Compressive } \\
\text { Strength (MPa) }\end{array}$} \\
\hline & & Cement & $\begin{array}{l}\text { Fly } \\
\text { Ash }\end{array}$ & $\begin{array}{l}\text { Silica } \\
\text { Fume }\end{array}$ & $\begin{array}{l}\text { Quartz } \\
\text { Sand }\end{array}$ & $\begin{array}{l}\text { Coarse } \\
\text { Aggregate }\end{array}$ & $\begin{array}{l}\text { Steel } \\
\text { Fibre }\end{array}$ & Superplasticizer & Water & & \\
\hline PC-1 & 0.13 & 2344 & 0 & 0 & 0 & 0 & 0 & 117.2 & 234.4 & 0.0 & 108.8 \\
\hline PC-2 & 0.17 & 2344 & 0 & 0 & 0 & 0 & 0 & 58.6 & 363.3 & 0.0 & 135.1 \\
\hline PC-3 & 0.21 & 2344 & 0 & 0 & 0 & 0 & 0 & 9.4 & 486.6 & 0.0 & 113.3 \\
\hline PCF-1 & 0.13 & 1875 & 469 & 0 & 0 & 0 & 0 & 152.3 & 213.3 & 0.0 & 123.1 \\
\hline PCF-2 & 0.17 & 1875 & 469 & 0 & 0 & 0 & 0 & 105.5 & 335.2 & 0.0 & 137.5 \\
\hline PCF-3 & 0.21 & 1875 & 469 & 0 & 0 & 0 & 0 & 46.9 & 464.1 & 0.0 & 109.1 \\
\hline PCS-1 & 0.13 & 1875 & 0 & 469 & 0 & 0 & 0 & 93.8 & 248.4 & 0.0 & 91.8 \\
\hline PCS-2 & 0.17 & 1875 & 0 & 469 & 0 & 0 & 0 & 46.9 & 370.3 & 0.0 & 100.6 \\
\hline PCS-3 & 0.21 & 1875 & 0 & 469 & 0 & 0 & 0 & 9.4 & 486.6 & 0.0 & 112.5 \\
\hline NC-1 & 0.30 & 440 & 0 & 0 & 755 & 1233 & 0 & 5.3 & 128.8 & 0.0 & 71.3 \\
\hline NC-2 & 0.42 & 360 & 0 & 0 & 693 & 1130 & 0 & 2.5 & 149.7 & 0.0 & 49.21 \\
\hline HPC-1 & 0.30 & 330 & 110 & 0 & 755 & 1233 & 0 & 5.3 & 128.8 & 0.0 & 69.2 \\
\hline HPC-2 & 0.42 & 270 & 90 & 0 & 693 & 1130 & 0 & 2.5 & 149.7 & 0.0 & 47.1 \\
\hline HPC-3 & 0.45 & 270 & 90 & 0 & 693 & 1130 & 0 & 2.5 & 160.5 & 0.0 & 46.5 \\
\hline HPC-4 & 0.31 & 308 & 132 & 0 & 565 & 565 & 0 & 5.3 & 133.2 & 0.0 & 48.4 \\
\hline HPC-5 & 0.45 & 220 & 120 & 0 & 457 & 686 & 0 & 2.7 & 151.4 & 0.0 & 49.1 \\
\hline uhpc-1 & 0.20 & 706 & 0 & 160 & 1409 & 0 & 0 & 21.0 & 160.6 & 0.0 & 102.3 \\
\hline uhpc-2 & 0.20 & 706 & 0 & 160 & 1249 & 0 & 160 & 21.0 & 160.6 & 2.0 & 130.4 \\
\hline UHPC-3 & 0.20 & 706 & 0 & 160 & 1249 & 0 & 160 & 74.0 & 128.8 & 2.0 & 154.7 \\
\hline UHPC-4 & 0.20 & 1957 & 0 & 443 & 0 & 0 & 0 & 74.0 & 435.6 & 2.0 & 115.6 \\
\hline
\end{tabular}

\subsection{Method}

Capillary water absorption tests of cement-based materials usually apply the weighing method, which includes the upwards, side, and downwards suction methods. The most commonly used method is the downwards suction method, as shown in Figure 1. In this experiment, before a specimen of cement-based material was exposed to water, the specimen was first dried in an oven at $105^{\circ} \mathrm{C}$ to a constant weight and weighed with an accuracy of $0.1 \mathrm{~g}$, and then all surfaces, except the test surface, were sealed with epoxy resin to ensure one-directional transport of water. After the epoxy cured, the specimen was placed with the test surface facing down on a support frame in a water tank at a temperature of $20 \pm 1^{\circ} \mathrm{C}$. During the test, the water level was maintained at $5 \mathrm{~mm}$ above the bottom of the specimen, and the specimen was removed every $15 \mathrm{~min}$. The surface moisture was removed with a damp cloth, the specimen was weighed immediately, and the condition of the specimen was observed. The total test time was at least $8 \mathrm{~h}$. 


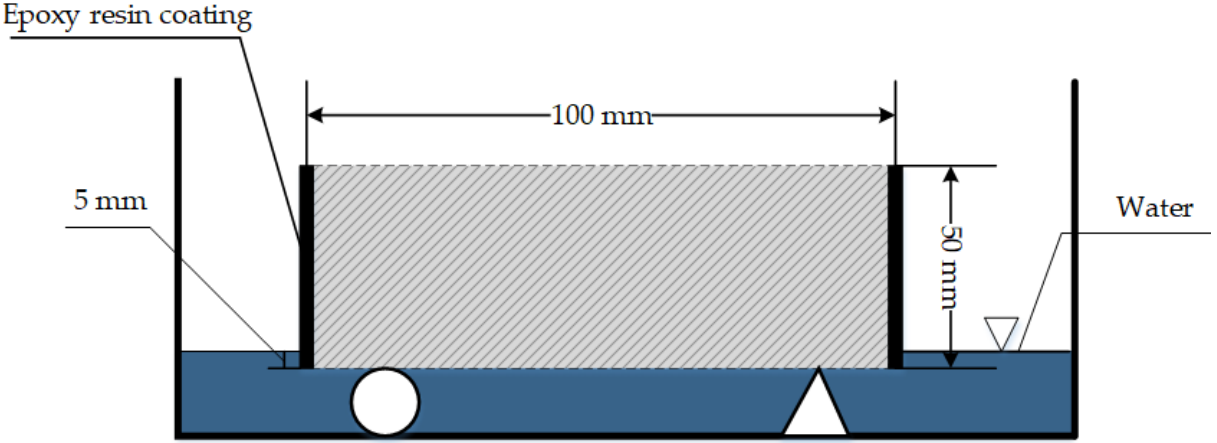

Figure 1. Diagram of the capillary water absorption test.

Since only one side of a specimen absorbed water during the test, a one-dimensional model was generally used to analyze the test results, and the extended version of Darcy's law was adopted. We assumed that the pore structure of the concrete did not change during the test, and the Boltzmann variable $[29,30] \lambda(\theta)=x / t^{1 / 2}$ was introduced. The Richards equation was obtained, as shown in Equation (1), where $x$ is the depth of capillary water absorption. The water absorption per unit area of cement-based materials tended to be linearly proportional to the square root of time. This law is also known as the square root law:

$$
V_{\mathrm{w}}(t)=\int_{\theta_{\text {init }}}^{\theta_{\text {cap }}} x d \theta=\sqrt{t} \int_{\theta_{\text {init }}}^{\theta_{\text {cap }}} \lambda(\theta) d \theta=S \sqrt{t},
$$

where $V_{\mathrm{w}}(t)$ is the water absorption of the test piece at $t, \theta$ is the water content, $t$ is the elapsed time, $\theta_{\text {cap }}$ is the boundary water content when the capillary is saturated during the absorption process, $\theta_{\text {init }}$ is the initial water content, and $S$ is the capillary water absorption coefficient. However, the test results showed that the curve fitted to the water absorption vs. square root of time did not pass through the origin. Therefore, Formula (2) was typically used to analyze the test results [31], and a was the intercept:

$$
V_{\mathrm{w}}=S t^{1 / 2}+a,
$$

Although Equation (2) was used to analyze the test results, many studies have shown that the initial cumulative water absorption by cement-based materials obeys the square root law. As the water absorption time increased, a deviation was observed. Therefore, many scholars have divided the absorption process into sections and analyzed it in two stages to obtain the first-stage capillary water absorption coefficient and the second-stage capillary water absorption coefficient (represented as $S_{1}$ and $S_{2}$ below, respectively). Generally, the change in the capillary water absorption coefficient is presumed to be related to the two behaviors described below. First, the presence of moisture inside the cement-based materials causes the continuous dissolution, leaching, and precipitation of loose substances such as calcium hydroxide, which changes the pore structure and affects the capillary water absorption properties of cement-based materials. Second, the C-S-H gel inside the cement-based material undergoes a change in shape with increasing water absorption, which alters its internal pore structure and affects the capillary water absorption properties of the cement-based material specimen [32]. Indeed, researchers no longer assume that the capillary water absorption properties of cement-based materials follow the square root law [33]. This second reason is generally believed to explain the two-stage behaviour for the capillary water absorption vs. the square root of time.

The capillary water absorption of cement-based materials is a good parameter to characterize their impermeability, but the composition of cement-based materials is complex, and the capillary water absorption characteristics are affected by various factors, such as the water-binder ratio, mineral admixture dosage, and damage. Studies aiming to clarify the effects of these factors on the capillary water absorption characteristics are very important to determine the impermeability and durability of cement-based materials. Compared 
with $S_{2}$ in the second stage, the capillary water absorption coefficient $S_{1}$ in the first stage better indicates the effects of different factors (such as the water-binder ratio, the type and dosage of mineral admixtures, the preload, specimen size [34], curing age, etc.) on the capillary water absorption performance of cement-based materials. Among them, the water-binder ratio, the type and dosage of fly ash and ground granulated blast furnace slag, and the preload are the factors on which scholars have mainly focused. Therefore, in the present study, $S_{1}$ was selected to analyze the effect of the four factors mentioned above on the capillary water absorption characteristics of cement-based materials and the relationship between capillary water absorption characteristics and pore structure. Compressive strength tests were performed according to standard GB/T 50081 [35]. MIP was conducted to analyze the variations in pore structures using a Poremaster-60 GT mercury porosimeter (Quantachrome Instruments, Florida, USA); the measured pore-size range was $3 \sim 950,000 \mathrm{~nm}$, and the maximum working pressure was 60,000 Pa. MIP samples were composed of a number of blocky particles approximately $5 \mathrm{~mm}$ in size with a total weight of approximately $2 \mathrm{~g}$. The pore structure of concrete changes under the action of environmental thermal fatigue cycles. The specific operation of the environmental thermal fatigue test was as follows: the test specimens were first placed in a drying oven and heated to $65^{\circ} \mathrm{C}$ over a period of $20 \mathrm{~min}$ and then dried at this temperature for $5 \mathrm{~h}$. After the test specimens were removed from the oven, they were quenched in $20^{\circ} \mathrm{C}$ running water for $30 \mathrm{~min}$ to reduce the surface temperature of the test specimen to $20^{\circ} \mathrm{C}$. Then, the specimens were heated again using the same process. This heating and quenching cycle is referred to as the environmental thermal fatigue (ETF) test [36].

\section{Results}

\subsection{Capillary Water Absorption Coefficient in the Presence of Different Water-Binder Ratios}

The first-stage capillary water absorption coefficients of cement-based materials with different mix proportions measured by the gravimetric method are shown in Table 3.

Table 3. Capillary water absorption coefficients for different water-binder ratios $\left(10^{-4} \mathrm{~mm} \cdot \mathrm{s}^{-1 / 2}\right)$.

\begin{tabular}{ccccccccccc}
\hline Code & PC-1 & PC-2 & PC-3 & PCF-1 & PCF-2 & PCF-3 & PCS-1 & PCS-2 & PCS-3 & NC-1 \\
\hline$S_{1}$ & 9.9 & 29.1 & 4.6 & 21.2 & 12.1 & 28.6 & 10.1 & 12.7 & 49.8 & 42.1 \\
\hline Code & NC-2 & HPC-1 & HPC-2 & HPC-3 & HPC-4 & HPC-5 & UHPC-1 & UHPC-2 & UHPC-3 & UHPC-4 \\
\hline$S_{1}$ & 56.2 & 39.8 & 51.5 & 76.6 & 224.9 & 306.5 & 23.3 & 28.4 & 54.7 & 47.5 \\
\hline
\end{tabular}

The capillary absorption coefficients of specimens PC- 1 to HPC- 3 were analyzed, as shown in Figure 2, without considering the effects of the steel fiber admixture and the cement-sand ratio. Figure 2 shows that the change in the capillary water absorption coefficient in cement-based materials was linearly related to the water/binder ratio (W/B) $\left(R^{2}=0.746\right)$, and the water-binder ratio exerted an obvious effect on the capillary water absorption coefficient. When the water-cement ratio increased from 0.13 to 0.45 , the capillary water absorption coefficient of the cement-based materials increased by approximately $400 \%$. The increase in $\mathrm{W} / \mathrm{B}$ led to a greater water content and less cement content per unit volume; the lower the $\mathrm{W} / \mathrm{B}$ of cement-based materials, the smaller the pore diameter and the lower the water absorption capacity of the cement-based materials. Conversely, the higher the $\mathrm{W} / \mathrm{B}$, the higher the absorption capacity of the cement-based material. In other words, the W/B affected the capillary water absorption performance of cement-based materials by changing their pore structure characteristics. 


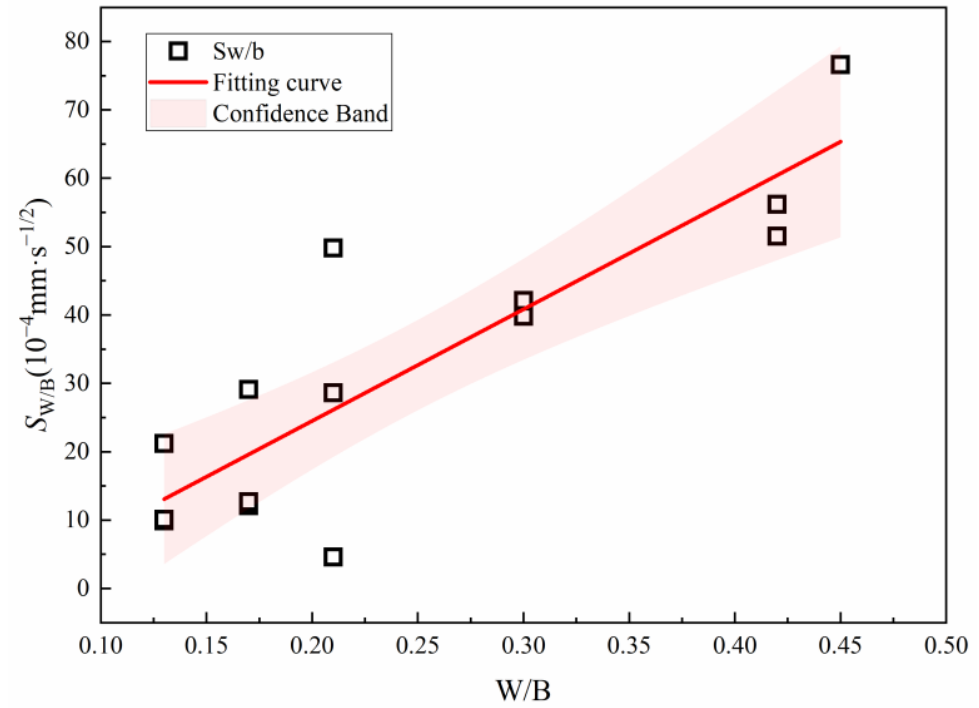

Figure 2. Relationship between the capillary water absorption coefficient and the W/B.

\subsection{Capillary Water Absorption Coefficient under Different Preload Levels}

Uniaxial compression loads with different preload levels $(0,50,70,90$, and $100 \%$ of the ultimate compressive load determined at $28 \mathrm{~d}$ ) were applied on cubic UHPC specimens to study the effect of preload-mediated damage on the capillary water absorption characteristics of concrete. The preload levels of UHPC-1 were 0, 50, 70, and 90\%. As steel fibers increased the toughness of UHPC, UHPC-2 was intact after a $100 \%$ preload level was applied.

The ultrahigh performance concrete specimens, UHPC-1 and UHPC-2, were subjected to the capillary water absorption test after different degrees of preloading. The measured capillary water absorption coefficients are shown in Table 4 . Table 4 shows that the addition of steel fibers increased the capillary water absorption coefficient. The curve of the capillary water absorption coefficient of specimens UHPC-1 and UHPC-2 vs. the precompression load is shown in Figure 3.

Table 4. Capillary water absorption coefficients for samples with different preload levels $\left(10^{-4} \mathrm{~mm} \cdot \mathrm{s}^{-1 / 2}\right)$.

\begin{tabular}{cccccc}
\hline \multirow{2}{*}{ Code } & \multicolumn{5}{c}{ Preload Level } \\
\cline { 2 - 6 } & $\mathbf{0 \%}$ & $\mathbf{5 0 \%}$ & $\mathbf{7 0} \%$ & $\mathbf{9 0 \%}$ & $\mathbf{1 0 0} \%$ \\
\hline UHPC-1 & 23.3 & 18.3 & 20.6 & 23.2 & \\
UHPC-2 & 28.4 & & 31.5 & & 51.1 \\
\hline
\end{tabular}

As shown in Figure 3, the capillary water absorption coefficient of UHPC changed with increasing preload levels. As the preload level increased, the capillary water absorption coefficient of the UHPC-1 specimens decreased and then increased. The capillary water absorption coefficients of samples under $0,50,70$, and $90 \%$ preloads were $23.3 \times 10^{-4}$, $18.3 \times 10^{-4}, 20.6 \times 10^{-4}$, and $23.2 \times 10^{-4} \mathrm{~mm} \cdot \mathrm{s}^{-1 / 2}$, respectively. For these preloaded specimens, the capillary water absorption coefficient was $21.46,11.59$, and $0.43 \%$ lower than the capillary water absorption coefficient of samples under no preload $(0 \%)$. In addition, the capillary water absorption coefficients of the UHPC-2 specimens under $0 \%, 70 \%$, and $100 \%$ preloads were $28.4 \times 10^{-4}, 31.5 \times 10^{-4}$, and $51.1 \times 10^{-4} \mathrm{~mm} \cdot \mathrm{s}^{-1 / 2}$, respectively. Figure 3 shows that the critical value of the effect of the preload on the capillary water absorption coefficient of cement-based materials is approximately $50 \%$, and the critical value will also change for different cement-based materials. For cement-based materials, when the preload level did not exceed the critical stress value, the compactness of the samples increased with an increasing preload level. When the preload level exceeded the 
critical stress value, more cracks formed inside the cement-based materials, and the water absorption capacity increased; thus, the capillary water absorption coefficient increased.

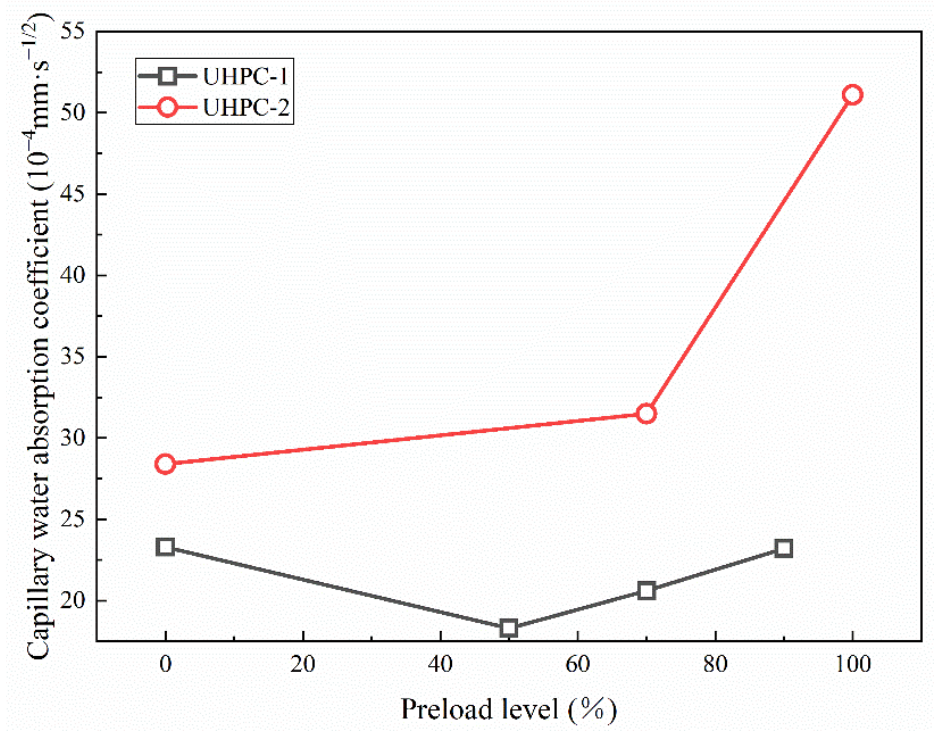

Figure 3. Capillary water absorption coefficients for different preload levels.

\subsection{Relationship between the Capillary Water Absorption Coefficient and Pore Structure}

Specimens NC-1, NC-2, HPC-1, and HPC-2 were subjected to ETF, and concrete specimens UHPC-1 and UHPC-2 were not subjected to ETF cycles to investigate the relationship between the concrete capillary water absorption coefficient and porosity. The pore structure of concrete changed through the action of ETF cycles. For NC, HPC, and UHPC specimens, the porosity and most probable pore size were measured using the MIP method, and capillary water absorption coefficients were obtained using the gravimetric method; the results are shown in Table 5.

Table 5. Capillary water absorption coefficients for different porosities.

\begin{tabular}{|c|c|c|c|c|c|c|c|}
\hline Code & NC-1-1 & NC-1-2 & NC-1-3 & NC-2-1 & NC-2-2 & NC-2-3 & HPC-1-1 \\
\hline Porosity $(\%)$ & 9.4 & 9.1 & 11.1 & 12.7 & 12.1 & 13.0 & 9.8 \\
\hline Capillary water absorption $\left(10^{-4} \mathrm{~mm} \cdot \mathrm{s}^{-1 / 2}\right)$ & 42.1 & 37.8 & 44.9 & 56.2 & 50.8 & 59.7 & 39.8 \\
\hline Most probable pore size $(\mathrm{nm})$ & 6.4 & 12.6 & 6.1 & 27.1 & 28.6 & 42.4 & 12.0 \\
\hline Code & HPC-1-2 & HPC-1-3 & HPC-2-1 & HPC-2-2 & HPC-2-3 & UHPC-1 & UHPC-2 \\
\hline Porosity $(\%)$ & 8.0 & 10.8 & 13.4 & 12.4 & 13.4 & 5.7 & 5.4 \\
\hline Capillary water absorption $\left(10^{-4} \mathrm{~mm} \cdot \mathrm{s}^{-1 / 2}\right)$ & 32.3 & 37.1 & 51.5 & 44.7 & 50.4 & 54.7 & 47.5 \\
\hline Most probable pore size $(\mathrm{nm})$ & 4.2 & 4.2 & 30.8 & 6.0 & 42.2 & 4.1 & 4.2 \\
\hline
\end{tabular}

The first 12 groups of specimens were NC-1, NC-2, HPC-1, and HPC-2 after 0, 90, and 330 ETF cycles, and the latter two groups were concrete specimens UHPC-1 and UHPC-2 without ETF cycles.

The capillary water absorption coefficient of concrete with different porosities is shown in Figure 4 . The capillary water absorption coefficient and the porosity were approximately linearly correlated (correlation coefficient $\mathrm{R}^{2}=0.749$ ). The capillary water absorption coefficient increased by approximately $21.9 \times 10^{-4} \mathrm{~mm} \cdot \mathrm{s}^{-1 / 2}$ when the porosity increased from 8.0 to $13.6 \%$. 


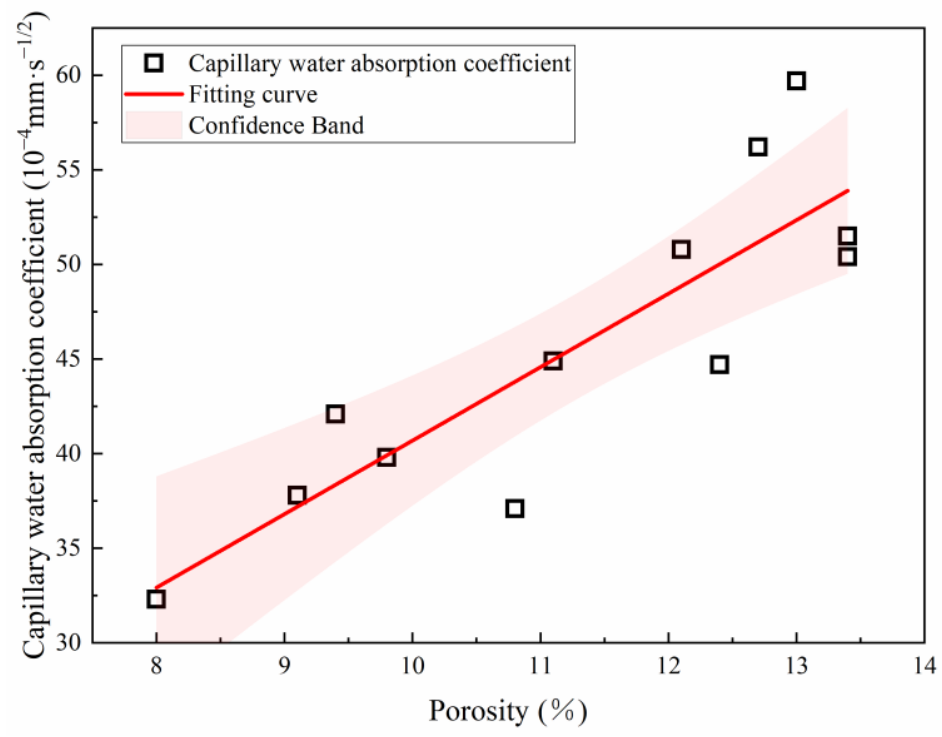

Figure 4. Relationship between the capillary water absorption coefficient and porosity.

The NC-2 specimens (after 0, 90, and 330 ETF cycles) and the UHPC-1 and UHPC-2 specimens (no ETF cycles) were evaluated using the MIP method to determine the internal pore distribution. The results are shown in Table 6.

Table 6. Pore volumes for various concrete samples with different pore size ranges $\left(10^{-3} \mathrm{~mL} \cdot \mathrm{g}^{-1}\right)$.

\begin{tabular}{|c|c|c|c|c|c|c|c|}
\hline \multirow[b]{2}{*}{ Code } & \multirow[b]{2}{*}{$S_{1}\left(10^{-4} \mathrm{~mm} \cdot \mathrm{s}^{-1 / 2}\right)$} & \multicolumn{6}{|c|}{ Pore-Size Range } \\
\hline & & $\begin{array}{c}\text { 3 10 } \\
\mathrm{nm}\end{array}$ & $\begin{array}{c}10 \sim 50 \\
\mathrm{~nm}\end{array}$ & $\begin{array}{c}50 \sim 100 \\
\mathrm{~nm}\end{array}$ & $\begin{array}{c}100 \sim 1000 \\
\mathrm{~nm}\end{array}$ & $\begin{array}{c}1000 \sim 10,000 \\
\mathrm{~nm}\end{array}$ & $\begin{array}{c}10,000 \sim 20,000 \\
\mathrm{~nm}\end{array}$ \\
\hline NC-2-1 & 59.65 & 2.81 & 12.03 & 5.60 & 6.46 & 2.82 & 0.92 \\
\hline NC-2-2 & 56.20 & 2.80 & 11.04 & 3.40 & 5.20 & 3.00 & 0.80 \\
\hline NC-2-3 & 50.80 & 2.60 & 9.76 & 3.59 & 4.56 & 2.47 & 1.00 \\
\hline UHPC-3 & 54.73 & 6.70 & 3.30 & 1.50 & 5.20 & 3.10 & 1.10 \\
\hline UHPC-4 & 47.50 & 6.85 & 2.05 & 0.90 & 2.70 & 4.10 & 1.60 \\
\hline
\end{tabular}

The first three groups are the NC-2 concrete specimens after 0, 90, and 330 ETF cycles, and the last two groups are UHPC-3 and UHPC-4 without ETF cycles.

As shown in Table 6, although the porosity differed, the capillary water absorption coefficients corresponding to the cement-based materials were similar; namely, the distribution of the internal pore structure of the cement-based materials exerted a substantial effect on its capillary water absorption performance. The pore volume distributions inside the concrete specimens with similar porosities were also quite different.

\section{Discussion}

\subsection{Effects of Different Factors on the Capillary Water Absorption of Concrete}

The effects of the $\mathrm{W} / \mathrm{B}$, fly ash and silica fume content, and preload level on the capillary water absorption characteristics of concrete were studied based on the results from the tests described above and complemented by a study of the literature and a theoretical analysis.

\subsubsection{Effect of the $\mathrm{W} / \mathrm{B}$}

The $\mathrm{W} / \mathrm{B}$ is an index that can reflect the permeability and compactness of cement-based materials and exerts a statistically significant effect on the capillary water absorption characteristics of cement-based materials. Through the investigation of the literature $[11,37-46]$ and the analysis of the test results, the values of the capillary water absorption coefficient of cement-based materials with different W/B values were obtained, as shown in Figure 5. The W/B exerted a statistically significant effect on $S_{1}$, which increased with an increasing $\mathrm{W} / \mathrm{B}$. The exponential function was used to fit the curve, and the result is shown in 
Equation (3) (correlation coefficient $R^{2}=0.790$ ). When the W/B increased from 0.30 to 0.40 and 0.50 , the first-stage capillary water absorption coefficient increased by approximately 89.82 and $260.31 \%$, respectively. The explanation for this finding is that the total porosity of concrete increased, the ability of cement-based materials to absorb and accommodate water increased, the microscopic pore structure changed, the pore size became larger, and the connectivity between the pores improved as the $\mathrm{W} / \mathrm{B}$ increased, which increased the water absorption capacity of the cement-based materials. Therefore, an appropriate $\mathrm{W} / \mathrm{B}$ should be selected to ensure good impermeability of cement-based materials.

$$
S_{\mathrm{W} / \mathrm{B}}=7.946 e^{6.409 \mathrm{~W} / \mathrm{B}}-0.01,
$$

where $S_{\mathrm{W} / \mathrm{B}}$ is the first-stage capillary water absorption coefficient at different $\mathrm{W} / \mathrm{B}$; $\left(10^{-4} \mathrm{~mm} \cdot \mathrm{s}^{-1 / 2}\right)$.

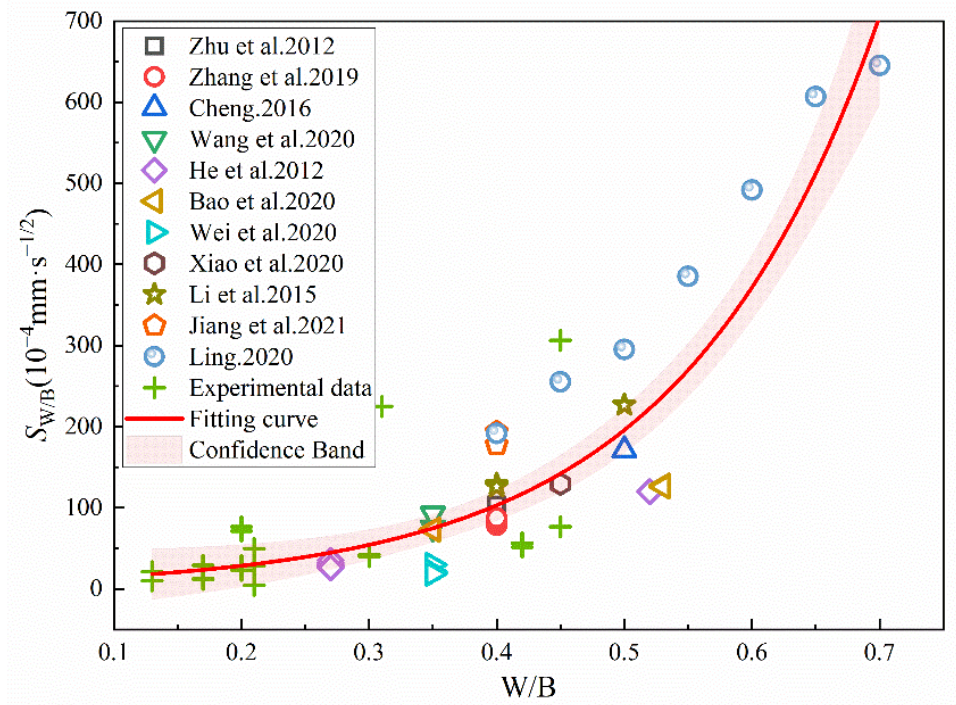

Figure 5. Effect of the $\mathrm{W} / \mathrm{B}$ on $S_{1}$.

\subsubsection{Effect of the Fly Ash Content}

Mineral admixtures such as fly ash increase the durability of cement-based materials and influence capillary water absorption characteristics. Figure 6 shows the effect of fly ash content on $S_{1}[4,19,45,47-51]$. The data from the literature were unified and normalized $\left(S_{\mathrm{r}}\right)$ to more intuitively analyze the influence of fly ash content and exclude the effect of the W/B; namely, the capillary water absorption coefficient without fly ash was 1 . Figure 6 shows that the dosage of fly ash exerts an obvious effect on $S_{1}$. When the dosage of fly ash diid not exceed the critical value, $S_{1}$ showed a decreasing trend with an increasing dosage of fly ash. The rational function was used for the fitting analysis, and the result is shown in Equation (4) (correlation coefficient $R^{2}=0.974$ ). When the fly ash content increased from 0 to 30 and $40 \%, S_{1}$ decreased by approximately 27.8 and $14.2 \%$, respectively. This finding is attributed to the improvement in the microstructure and increase in the density of the pore structure when an appropriate dosage of fly ash was added to cement-based materials, making it greater, which increased the difficulty for water to enter the interior and thus increased the durability. Therefore, in cement-based material production, an appropriate amount of mineral admixtures can be mixed, increasing the permeability and durability of cement-based materials.

$$
S_{\mathrm{r}}=\frac{1-0.01546 M_{\mathrm{f}}}{1+0.00723 M_{\mathrm{f}}-5.279 \times 10^{-4}{M_{\mathrm{f}}}^{2}},
$$

where $S_{\mathrm{r}}$ is the normalized $S_{1}$ for different fly ash dosages, and $M_{\mathrm{f}}$ is the fly ash dosage (\%). 


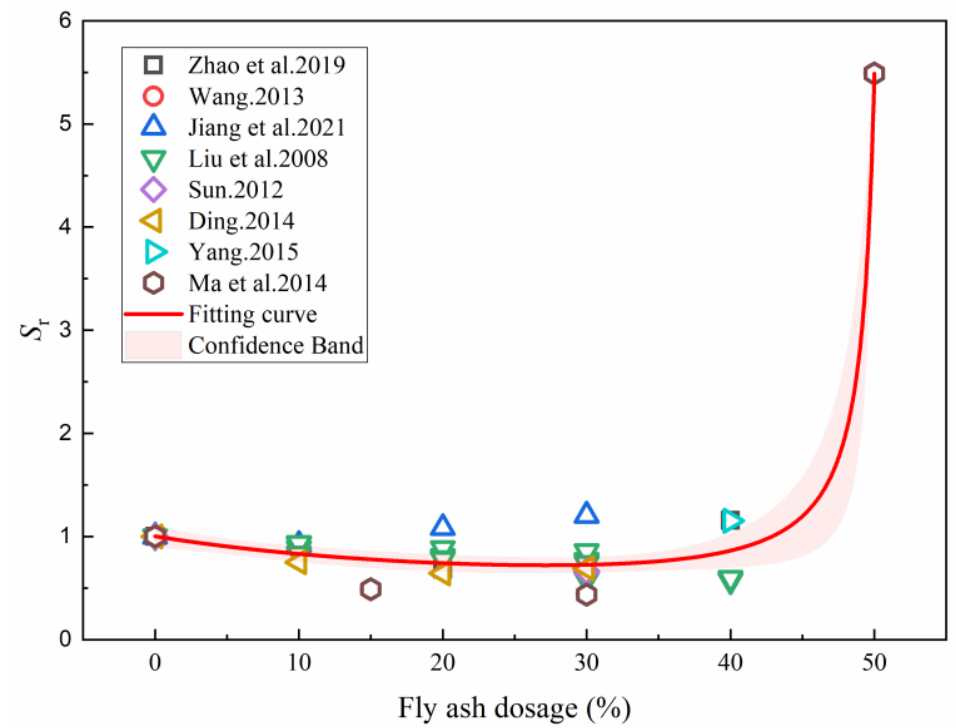

Figure 6. Effect of the fly ash dosage on $S_{1}$.

\subsubsection{Effect of the Ground Granulated Blast Furnace Slag Dosage}

Mohammed [52] found that the use of slag cement increases the density of the surface structure of a cement-based material denser and simultaneously improves the interface transition zone, which substantially improves its anti-erosion ability. As shown in the study by He et al. [53] mixing ground granulated blast furnace slag with concrete causes a statistically significant improvement in the $6 \mathrm{~h}$ resistance of concrete to chloride ions and results in a statistically significant reduction in the penetration depth of chloride ions. The addition of ground granulated blast furnace slag effectively reduces the permeability of cement-based materials. Figure 7 shows the effect of the ground granulated blast furnace slag content on the capillary water absorption coefficient $[19,39,54-56]$; the data were normalized. As shown in Figure 7, with an increasing ground granulated blast furnace slag dosage, $S_{1}$ showed a decreasing trend. The linear function was used for a fitting analysis, and the relationship between the capillary water absorption coefficient and the dosage of ground granulated blast furnace slag was calculated using Equation (5) (correlation coefficient $R^{2}=0.869$ ). When the dosage of ground granulated blast furnace slag increased from 0 to 30 and $40 \%, S_{1}$ decreased by approximately 38.4 and $52.7 \%$, respectively. Mixing fly ash or ground granulated blast furnace slag in a cement-based material reduced its capillary water absorption coefficient and improved its impermeability. A comparison of the effects of two mineral admixtures on the capillary water absorption coefficient of cement-based materials showed that the effect of adding ground granulated blast furnace slag was better than that of adding fly ash with the same dosage.

$$
S_{\mathrm{rm}}=-0.0143 M_{\mathrm{m}}+1.045,
$$

where $S_{\mathrm{rm}}$ is the normalized $S_{1}$ obtained for materials with different ground granulated blast furnace slag dosages, and $M_{\mathrm{m}}$ is the ground granulated blast furnace slag dosage (\%). 


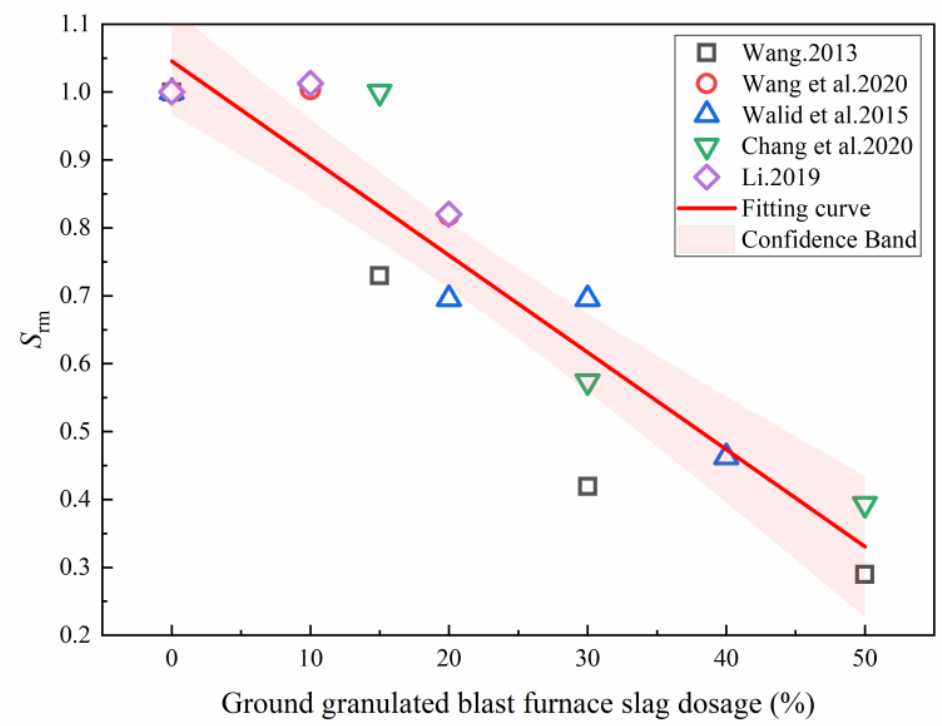

Figure 7. Effect of the ground granulated blast furnace slag dosage on $S_{1}$.

\subsubsection{Effect of the Preload Level}

According to recent studies, damage occurring under a load is closely related to the capillary water absorption coefficient of cement-based materials. Gerard et al. $[57,58]$ found that cracks induced in concrete under preloading substantially affected its capillary water absorption. Using neutron ray imaging technology, Zhang et al. [59] found that the crack propagation region had a stronger water absorption capacity than the intact region in cement-based materials. Figure 8 shows the effect of the preload level, $\lambda_{c}$, on the capillary water absorption performance of cement-based materials, based on results from the literature $[30,39,60-65]$ and two sets of UHPC test results; the capillary water absorption coefficient was normalized. The relationship between the capillary water absorption coefficient of cement-based materials and the preload was calculated using Equation (6) (correlation coefficient $R^{2}=0.697$ ). When the preload did not exceed $38 \%$, the capillary water absorption coefficient of cement-based materials decreased continuously with an increasing preload level. When it exceeded the critical value of $38 \%$, the capillary water absorption coefficient increased rapidly with increasing preload levels.

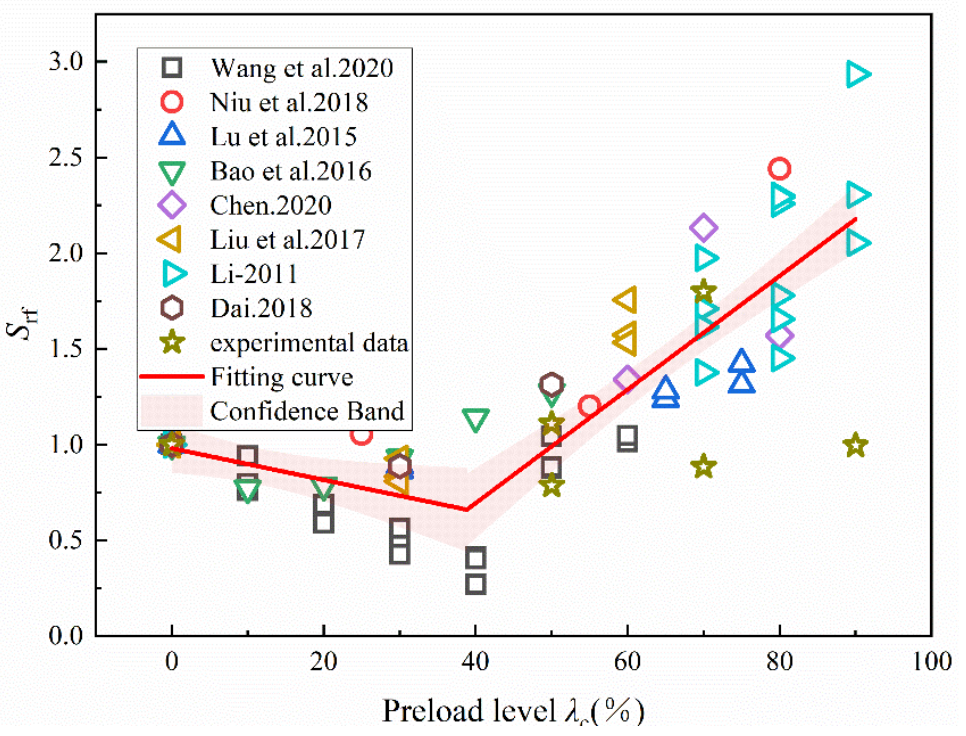

Figure 8. Effect of the preload level on $S_{1}$. 
For cement-based materials, when the applied compressive stress did not exceed the critical stress value, the interior was more compact than when the compressive stress exceeded the critical stress value, because excessive stress caused more cracks to form inside the cement-based material, the pore structure inside the specimens was destroyed, the water absorption capacity was increased, and the capillary water absorption coefficient increased. Thus, the preload level exerted a statistically significant effect on the capillary water absorption coefficient.

$$
\left\{\begin{array}{l}
S_{\mathrm{rf}}=0.980-0.00824 \lambda_{\mathrm{c}}, \lambda_{\mathrm{c}} \leq 38.85 \% \\
S_{\mathrm{rf}}=0.6599+0.02967\left(\lambda_{\mathrm{c}}-38.85\right), \lambda_{\mathrm{c}}>38.85 \%
\end{array},\right.
$$

where $S_{\mathrm{rf}}$ is the normalized $S_{1}$ under different preload levels, and $\lambda_{\mathrm{c}}$ is the preload level (\%).

As described above, we analyzed the individual effects of the $W / B$, mineral admixtures, and preload damage on the capillary water absorption coefficient. Further studies are needed to determine the effects of additional factors, such as specimen size, ambient temperature, fiber addition, and fiber type, on the capillary water absorption of cement-based materials.

\subsection{Relationship between Capillary Water Absorption and the Pore Structure}

\subsubsection{Porosities and Capillary Water Absorption Coefficients}

The capillary water absorption capacity of cement-based materials is related to their internal microstructure. By analyzing the literature $[4,37,38,42,46,66,67]$ and test results, the capillary water absorption coefficient, $S_{1}$, of cement-based materials with different porosities was obtained. Figure 9 analyses the relationship between the porosity of the cement-based material and the capillary water absorption coefficient. As the porosity of the cement-based material increased, its capillary water absorption coefficient showed an increasing trend. The specific trend between the capillary absorption coefficient and the porosity of cement-based materials is shown in Equation (7) (correlation coefficient $\mathrm{R}^{2}=0.766$ ). Here, the porosity is defined as the percentage of the pore volume inside the cement-based material relative to the total volume of the material, which largely characterizes the compactness of the cement-based material.

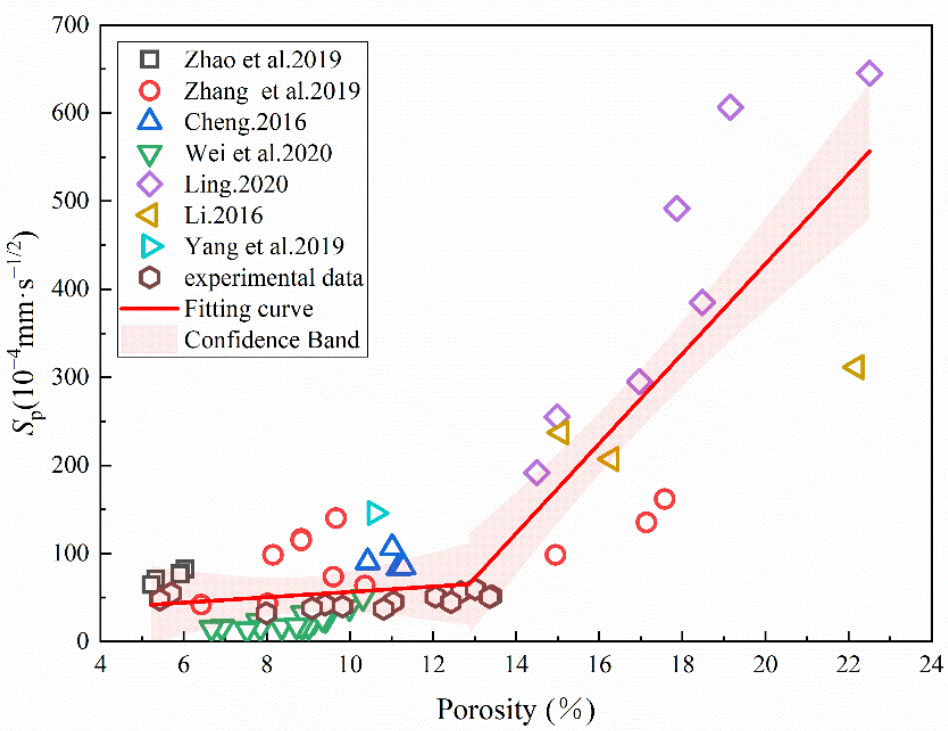

Figure 9. Relationship between porosity and $S_{1}$.

When the porosity of the cement-based material was less than the critical value of $12.87 \%$, its capillary water absorption coefficient increased slowly as the porosity increased. When the internal porosity of the cement-based material exceeded the critical value, the capillary water absorption coefficient increased rapidly as the porosity continued to increase. 
The capillary water absorption coefficient of cement-based materials exhibited two stages with the change in its internal porosity, indicating that the internal microstructure of cement-based materials fundamentally changed when the porosity exceeded a certain characteristic value.

The most probable pore size corresponds to the peak value in the pore size differential curve obtained from MIP measurements, i.e., the most likely pore size according to the pore size distribution. Therefore, the most probable pore size may accurately characterize the change in the internal microstructure of cement-based materials with changes in porosity.

$$
\left\{\begin{array}{l}
S_{\mathrm{p}}=3.045 \lambda_{\mathrm{p}}+25.937, \lambda_{\mathrm{p}} \leq 12.87 \% \\
S_{\mathrm{p}}=51.0\left(\lambda_{\mathrm{p}}-12.87\right)+65.13, \lambda_{\mathrm{p}}>12.87 \%
\end{array},\right.
$$

where $S_{\mathrm{p}}$ is the first-stage capillary water absorption coefficient of materials with different porosities $S_{1}\left(10^{-4} \mathrm{~mm} \cdot \mathrm{s}^{-1 / 2}\right)$, and $\lambda_{\mathrm{p}}$ is the porosity.

Many scholars have studied the classification of pore sizes in cement-based materials. At present, three common cement stone pore classification methods are mainly used, as shown in Table 7. Wu classified pore sizes according to their effects on the performance of cement-based materials, while the two other methods classified pores according to their type. The classification method reported by Boutt et al. is the most common method used in current research. Therefore, this paper applies the method reported by Boutt et al. to analyze the relationship between the porosity of cement-based materials and the most probable pore size. The results are shown in Figure 10.

Table 7. The classification of cement stone pores.

\begin{tabular}{ccc}
\hline Reference & Pore-Size Range & Classification \\
\hline & $\rho<20 \mathrm{~nm}$ & Harmless pore size \\
$20 \mathrm{~nm} \leq \rho \leq 50 \mathrm{~nm}$ & Less harmful pore size \\
& $50 \mathrm{~nm} \leq \rho \leq 200 \mathrm{~nm}$ & Harmful pore size \\
Zhongwei Wu [68] & $\rho>200 \mathrm{~nm}$ & Multi-hazardous pore size \\
& $10 \mathrm{~nm} \leq \rho \leq 100 \mathrm{~nm}$ & Gel pore \\
& $100 \mathrm{~nm} \leq \rho \leq 1000 \mathrm{~nm}$ & Transitional pore \\
Boutt et al. [69] & $\rho>1000 \mathrm{~nm}$ & Capillary pore \\
& $\rho<1.2 \mathrm{~nm}$ & Macropore \\
& $0.6 \mathrm{~nm} \leq \rho \leq 1.6 \mathrm{~nm}$ & Gel microcrystalline Inner \\
& $3.2 \mathrm{~nm} \leq \rho \leq 200 \mathrm{~nm}$ & holes \\
Kondo Renichi and Daimon & $\rho>200 \mathrm{~nm}$ & Gel inter-microcrystalline \\
Masaki [70] & Pores/gel pores \\
& Gel interparticle \\
& & pores/transition pores \\
& & Capillary pore/macropore \\
\hline
\end{tabular}

With the continuous increase in the porosity of the cement-based material, the most probable pore size of the cement-based material showed an increasing trend. When the porosity of the cement-based material was less than $11.43 \%$, the most probable pore size was in the range of the gel pores. When the porosity exceeded $11.43 \%$, the most probable pore size of the cement-based material transitioned from gel pores to capillary pores; thus, as the porosity of the cement-based material decreased, its internal pore structure was continuously refined. This result also explains why the capillary water absorption coefficient of the cement-based material exhibited a two-stage property with increasing porosity. When the porosity of the cement-based material was less than $12.87 \%$, namely, the proportion of the gel pores in the total pores was relatively large, the capillary water absorption effect was relatively weak, and rapid water absorption did not occur. With the continuous increase in porosity, the number of transition pores inside the cement-based material increased substantially, and the capillary water absorption effect increased rapidly. 


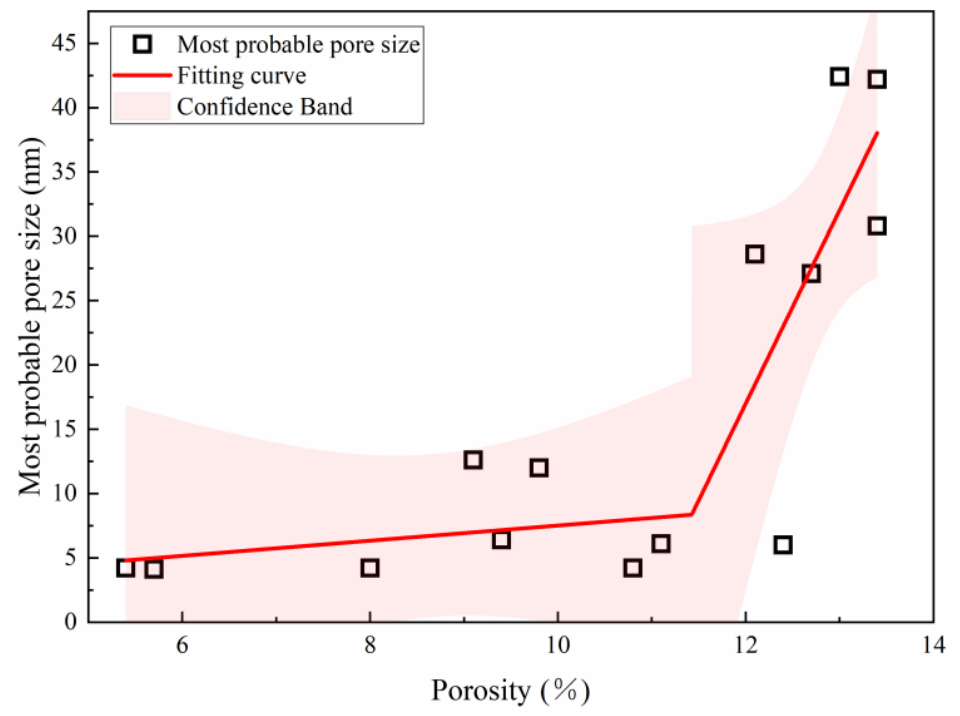

Figure 10. Relationship between porosity and the most probable pore size.

However, when different specimens had similar porosities inside their structures, their capillary water absorption performance varied substantially due to the state of the pores. Therefore, porosity alone does not reflect the specific pore distribution inside the material and the connectivity between pores. In other words, porosity did not fully represent the pore structure characteristics of cement-based materials, and the main factor affecting the capillary water absorption characteristics was the amount of pores within a certain size range.

\subsubsection{Pore Volumes and Capillary Water Absorption Coefficients in Different Pore Size Ranges}

The capillary water absorption performance of cement-based materials is closely related to their porosity, and the size and distribution of the pore size also exert important effects on their water absorption characteristics. When characterizing internal pore characteristics, the use of porosity alone does not fully explain the effect of pores on capillary water absorption. Therefore, the porosity and distribution of pores of each size must be considered together.

In this study, the relationship between pore volume and capillary water absorption in cement-based materials with different pore size ranges was studied using the method of pore size division described by Boutt et al. The pore structure distributions of the samples were determined using the MIP method (effective test range $\geq 3 \mathrm{~nm}$ ). Based on the classification of the pore structure described by Boutt et al., the pore size range was further refined, and the pore volumes in different pore size ranges were obtained. The volumes are shown in Figure 11, where the first to third groups are NC-2 specimens with different pore characteristics; the fourth and fifth groups are UHPC-3 and UHPC-4 specimens. It can be seen from Figure 11 that the most pores were in the range of 10 50 nm in diameter for NC-2 specimens and 3 10 $\mathrm{nm}$ for UHPC specimens. 


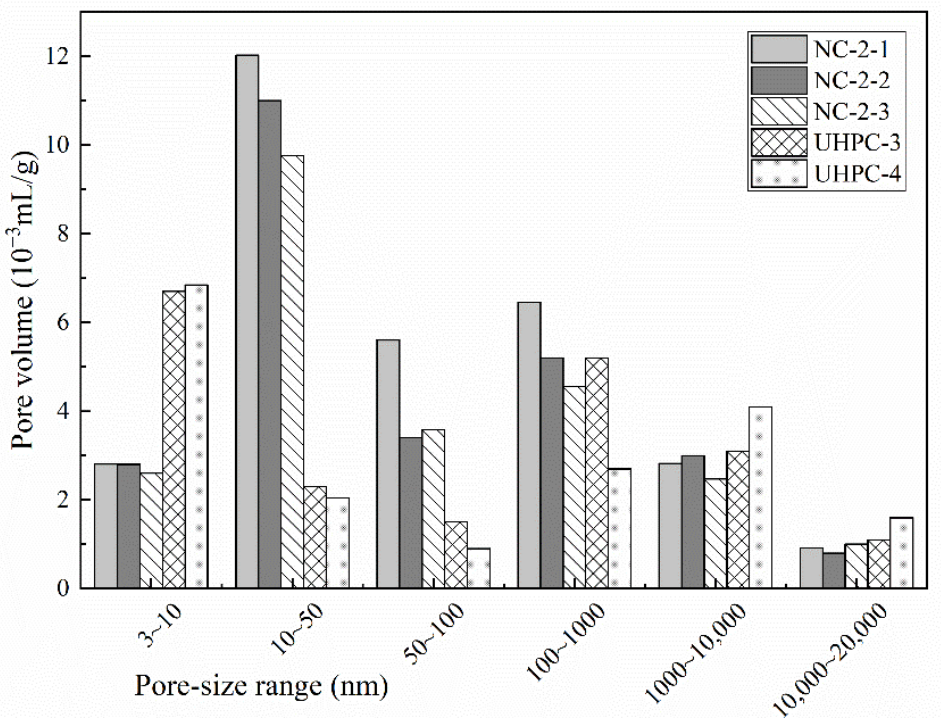

Figure 11. Statistical analysis of the pore content in different pore size ranges according to the method of pore size classification described by Boutt et al.

Figure 12 shows the relationship between the pore volume in different pore size ranges and the first-stage capillary water absorption coefficient. The pore volume contents of pore sizes larger than $1000 \mathrm{~nm}$ were similar, but the capillary water absorption coefficients of the cement-based material differed, and thus, the pore volume content of the pores larger than 1000 had little effect on the capillary water absorption coefficient of the cement-based material. With the increase in the pore volume in the range of $3 \sim 10 \mathrm{~nm}$, the capillary water absorption coefficient tended to decrease, because most of the pores in this range were gel pores, and water did not readily enter these pores during the capillary test. With the increase in pore volume in the range of $10 \sim 50 \mathrm{~nm}$, the capillary water absorption coefficient showed an increasing trend.

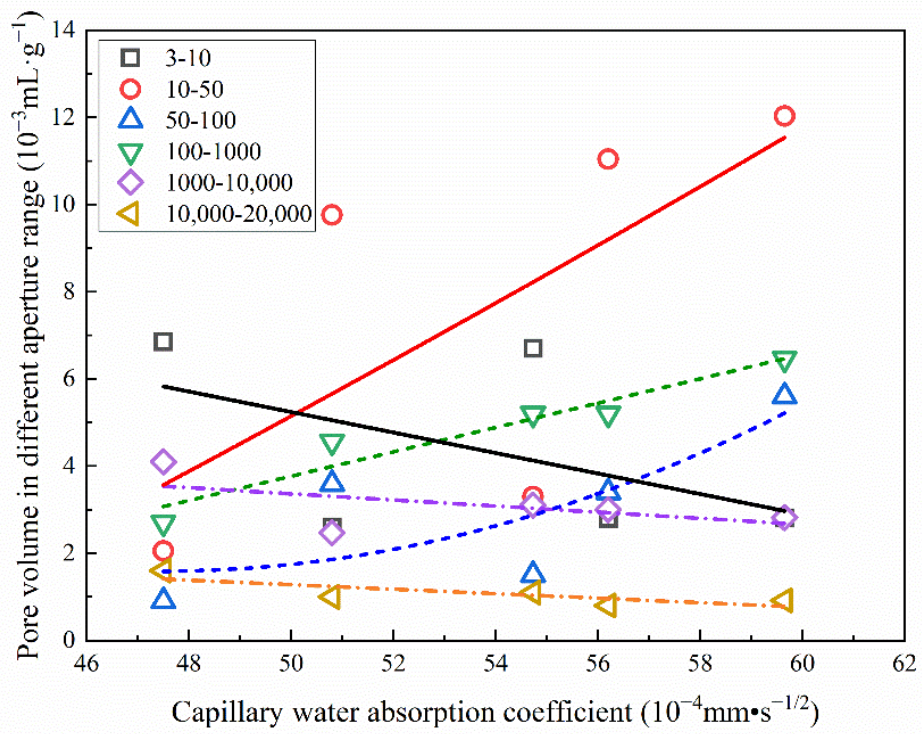

Figure 12. Relationship between the pore volume and capillary water absorption coefficient in different pore size ranges.

Based on the Menger sponge model [71] and von Koch curve theory [72], we calculated the pore fractal dimension corresponding to each of the five groups of tests by combining the results of MIP. Figure 13 analyzes the relationship between the pore fractal dimension 
and the capillary water absorption coefficient. Figure 13 shows that as the pore fractal dimension increased, the shape of the pore structure of cementitious materials became more complex, and the capillary water absorption coefficient also increased.

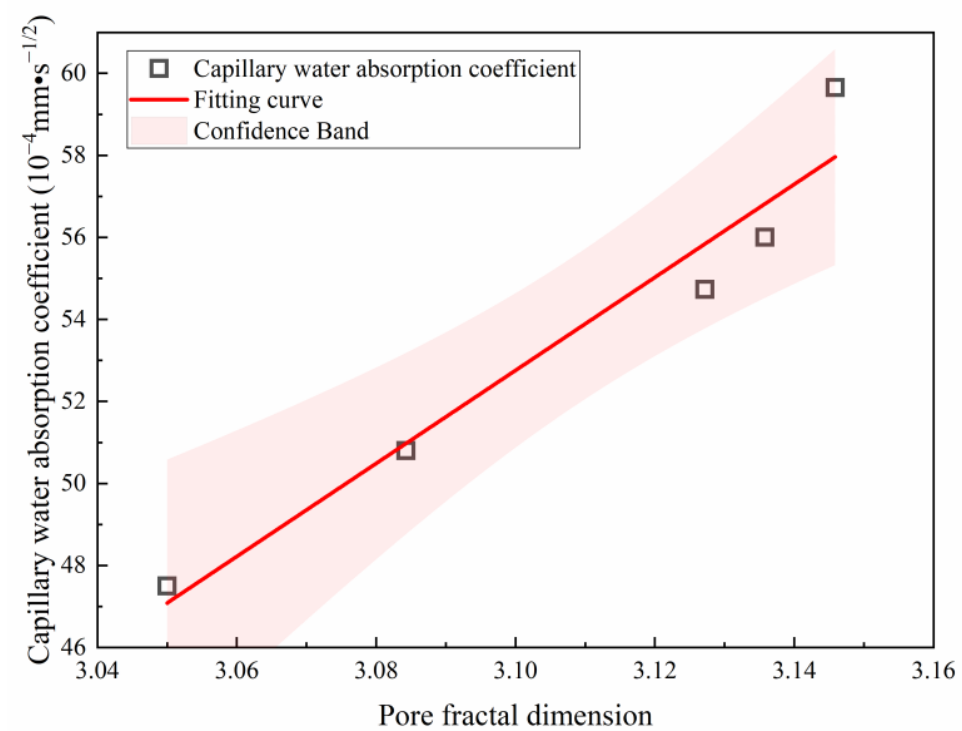

Figure 13. Relationship between the pore fractal dimension and the capillary water absorption coefficient.

In addition, with increases in pore volumes in the ranges of $50 \sim 100 \mathrm{~nm}$ and $100 \sim 1000 \mathrm{~nm}$, the capillary water absorption coefficient also showed an increasing trend, indicating that the increase in pore volume in these pore size ranges also led to an increase in the capillary water absorption capacity of cement-based materials. According to the slope of the curve, the pore content of the pore size range of 100 1000 exerted the greatest effect on the capillary water absorption coefficient, indicating that this pore size range had a major effect on capillary water absorption; capillary pores were the main pores that affected capillary water absorption. Therefore, controlling the pore volume in the range of $10 \sim 1000 \mathrm{~nm}$ inside cement-based materials, especially the number of pores within the range of 100 1000 nm, is the most effective method for controlling the capillary water absorption characteristics of cement-based materials; this finding is of great importance for improving the durability of concrete.

\section{Conclusions}

The capillary water absorption performance of cement-based materials is influenced by various factors. In the present study, the capillary water absorption coefficient of cement-based materials with different $\mathrm{W} / \mathrm{B}$ and various preloads was measured using the weight method, and the pore structure of specimens was determined using MIP. The following conclusions were drawn by analyzing the relationship between the capillary water absorption coefficient and the different influencing factors.

(1) With the increase in the W/B, the total porosity of cement-based materials increased, and the connectivity between the pores increased. The higher the $\mathrm{W} / \mathrm{B}$ was, the more rapid was the acceleration of the rate of water uptake during the initial absorption period.

(2) When the dosage of fly ash did not exceed the critical value, the capillary water absorption coefficient of all cement-based material samples decreased with increasing dosages of fly ash, which was beneficial and improved the impermeability of cement-based materials. However, when the dosage of fly ash exceeded the critical value, the capillary water absorption coefficient of cement-based materials increased rapidly with increasing dosages of fly ash. 
(3) With an increasing ground granulated blast furnace slag content, the capillary water absorption coefficient of the cement-based material decreased rapidly. Adding fly ash or ground granulated blast furnace slag effectively reduced the capillary water absorption coefficient of cement-based materials. Compared with the effect of fly ash, the ground granulated blast furnace slag exerted a more obvious effect on reducing the capillary water absorption coefficient.

(4) The experimental results showed that with an increasing preload, the capillary water absorption of the cement-based material first decreased and then increased. When the preload was low, the internal pores of the cement-based material closed, resulting in a decrease in the capillary water absorption coefficient. When the preload exceeded the critical value, as the preload increased, new microcracks formed and expanded inside the cement-based material, and the capillary water absorption coefficient increased.

(5) With increasing pore volumes in the pore size range of $10 \sim 50 \mathrm{~nm}$, the capillary absorption coefficient showed an increasing trend; with the increase in the pore volume in the ranges of 50 100 nm and 100 1000 nm, the capillary absorption coefficient first increased and then decreased slightly. Therefore, the ability of cement-based materials to absorb water is correlated mainly with pores with diameters ranging from 10 1000 nm. With the increase of the pore fractal dimension, the capillary water absorption coefficient continued to increase.

This study serves as an important step towards a more complete understanding of the capillary water absorption characteristics of concrete. Although the results of the present study are valid for the range of parameters we considered herein, further experiments should be conducted to confirm and expand the knowledge obtained from this study.

Author Contributions: Conceptualization, Y.W. and M.A.; methodology, Y.W., M.A., Z.Y. and H.H.; formal analysis, L.L.; investigation, L.L., Y.S. and H.H.; data curation, L.L., Y.S. and H.H.; writingoriginal draft preparation, Y.W. and L.L.; writing - review and editing, Y.W., M.A. and Z.Y. All authors have read and agreed to the published version of the manuscript.

Funding: This research was funded by the Fundamental Research Funds for the Central Universities, grant number 2019RC007; the National Natural Science Foundation of China, grant number 52108189; and the Beijing Natural Science Foundation, grant number 8192032.

Institutional Review Board Statement: Not applicable.

Informed Consent Statement: Not applicable.

Data Availability Statement: The data supporting the findings of the study are available within the article.

Acknowledgments: Financial support from the Fundamental Research Funds for the Central Universities (Grant No. 2019RC007), National Natural Science Foundation of China (Grant No. 52108189) and Beijing Natural Science Foundation (Grant No. 8192032) is greatly appreciated.

Conflicts of Interest: The authors declare no conflict of interest.

\section{References}

1. Medina, C.; de Rojas, M.S.; Frías, M. Properties of recycled ceramic aggregate concretes: Water resistance. Cem. Concr. Compos. 2013, 40, 21-29. [CrossRef]

2. Wang, L.C.; Bao, J.W. Prediction of the Cracking Effect on Mass Penetration into Unsaturated Concrete. Concrete 2015, 10, 387-396.

3. Gong, R.G. Effect of surface adsorption on concrete. J. Foreign Highw. 1995, 5, 54-56.

4. Zhao, H.T.; Ding, J.; Huang, Y.Y.; Tang, Y.M.; Huang, D.H. Experimental analysis on the relationship between pore structure and capillary water absorption characteristics of cement-based materials. Struct. Concr. 2019, 20, 1750-1762. [CrossRef]

5. Li, S.G.; Chen, G.X.; Ji, G.J.; Lu, Y.H. Quantitative damage evaluation of concrete suffered freezing-thawing by DIP technique Constr. Build. Mater. 2014, 69, 177-185. [CrossRef]

6. Yang, L.; Zhang, Y.S.; Liu, Z.Y.; Zhao, P.; Liu, C. In-situ tracking of water transport in cement paste using X-ray computed tomography combined with CsCl enhancing. Mater. Lett. 2015, 160, 381-383. [CrossRef]

7. Sabir, B.B.; Wild, S.; O'Farrell, M.A. Water sorptivity test for martar and concrete. Mater. Struct. 1998, 31, 568-574. [CrossRef]

8. Ramezanianpour, A.A.; Pilvar, A.; Mahdikhani, M.; Moodi, F. Practical evaluation of relationship between concrete resistivity, water penetration, rapid chloride penetration and compressive strength. Constr Build. Mater. 2010, 25, 2472-2479. [CrossRef] 
9. Zhan, S.W. Study on Transport Mechanism and Pore Structure of Alkali-Activated Slag Concrete in Freeze-Thaw and Chloride Composite Environment. Master's Thesis, Qingdao University of Technology, Qingdao, China, 2018.

10. Hou, D.; Zhao, T.; Ma, H.; Li, Z. Reactive Molecular Simulation on Water Confined in the Nanopores of the Calcium Silicate Hydrate Gel: Structure, Reactivity, and Mechanical Properties. J. Phys. Chem. C 2015, 119, 1346-1358. [CrossRef]

11. Zhu, F.Z.; Zhao, T.J.; Wang, P.G.; Ma, Z.M. Discussion of the affecting factors on concrete sorption capacity. J. Xi'an Univ. Archit. Technol. (Nat. Sci. Ed.) 2012, 44, 627-631+636.

12. Oltulu, M.; Şahin, R. Pore structure analysis of hardened cement mortars containing silica fume and different nano-powders Constr. Build. Mater. 2014, 53, 658-664. [CrossRef]

13. Mobili, A.; Telesca, A.; Marroccoli, M.; Tittarelli, F. Calcium sulfoaluminate and alkali-activated fly ash cements as alternative to Portland cement: Study on chemical, physical-mechanical, and durability properties of mortars with the same strength class. Constr. Build. Mater. 2020, 246, 118436. [CrossRef]

14. Gao, Q.; Ma, Z.M.; Xiao, J.Z.; Li, F.; Nematollahi, B. Effects of Imposed Damage on the Capillary Water Absorption of Recycled Aggregate Concrete. Adv. Mater. Sci. Eng. 2018, 1, 1-12. [CrossRef]

15. Luo, L.L. Effect of Rehydration on Properties of Cement-Based Materials with Low Water-Cement Ratio. Master's Thesis, Beijing Jiaotong University, Beijing, China, 2018.

16. Yang, L.; Zhang, Y.S.; Zhang, C.X. Water Transport and Permeability Coefficient Calculation for Unsaturated Cement-Based Materials Based on X-CT. Bull. Am. Ceram. Soc. 2020, 39, 3775-3782.

17. Shi, J.Y.; Liu, B.J.; Qin, J.L.; Jiang, J.Y.; Wu, X.; Tan, J.X. Experimental study of performance of repair mortar: Evaluation of in-situ tests and correlation analysis. J. Build. Eng. 2020, 31, 101325. [CrossRef]

18. Huang, H.F. Performance Evolution Mechanism of High Performance Concrete under the Action of Environmental Thermal Fatigue. Ph.D. Thesis, Beijing Jiaotong University, Beijing, China, 2020.

19. Wang, B.Z. Study on Chloride Ion Transportion in Unsaturated Concrete. Master's Thesis, Qingdao Technological University, Qingdao, China, 2013.

20. Tao, B. Effect of Concrete Pore Structure on Chloride Diffusivity. Master's Thesis, Wuhan University of Technology, Wuhan, China, 2009.

21. Wong, H.S.; Zobel, M.; Buenfeld, N.R.; Zimmerman, R.W. Influence of the interfacial transition zone and microcracking on the diffusivity, permeability and sorptivity of cement-based materials after drying. Mag. Concr. Res. 2009, 61, 571-589. [CrossRef]

22. Zeng, X.; Chen, L.; Zheng, K.; Ling, C.; Zhu, H.; Liu, H.; Wang, P.; Li, K.; Liu, Z.; Wang, M. Electrical resistivity and capillary absorption in mortar with styrene-acrylic emulsion and air-entrained agent: Improvement and correlation with pore structure. Constr. Build. Mater. 2020, 255, 119287. [CrossRef]

23. He, Z.H.; Long, G.C.; Xie, Y.J. Influence of subsequent curing on water sorptivity and pore structure of steam-cured concrete. J. Cent. South Univ. 2012, 19, 297-304. [CrossRef]

24. Zhang, L.S. Research on Characteristics of Internal and External Damage of Concrete in Freeze-Thaw Environment. Master's Thesis, Qingdao Technological University, Qingdao, China, 2010.

25. Ren, F.Z.; Zhou, C.S.; Zeng, Q.; Zhang, Z.D.; Ueli, A.; Wang, W. Quantifying the anomalous water absorption behavior of cement mortar in view of its physical sensitivity to water. Cem. Concr. Res. 2021, 143, 106395. [CrossRef]

26. Baricevic, A.; Pezer, M.; Rukavina, M.J.; Serdar, M.; Stirmer, N. Effect of polymer fibers recycled from waste tires on properties of wet-sprayed concrete. Constr. Build. Mater. 2018, 176, 135-144. [CrossRef]

27. Tasdemir, C. Combined effects of mineral admixtures and curing conditions on the sorptivity coefficient of concrete. Cem. Concr. Res. 2003, 33, 1637-1642. [CrossRef]

28. GB175-2007; Chinese National Standard, Chinese Cement: Common Portland Cement. China Association for Standardization: Beijing, China, 2007; pp. 2-6.

29. Hall, C. Water sorptivity of mortars and concrete:a review. Mag. Concr. Res. 1993, 419, 51-61.

30. Li, S.H. Theoretical and Experimental Study on the Capillary Absorption Within Concrete. Master's Thesis, Dalian University of Technology, Dalian, China, 2011.

31. Martys, N.S.; Ferraris, C.F. Capillary transport in mortars and concrete. Cem. Concr. Res. 1997, 27, 747-760. [CrossRef]

32. Bentz, D.P.; Garboczi, E.J. Modelling the leaching of calcium hydroxide from cement paste: Effects on pore space percolation and diffusivity. Mater. Struct. 1992, 25, 523-533. [CrossRef]

33. Zhou, C.S. Predicting water permeability and relative gas permeability of unsaturated cement-based material from hydraulic diffusivity. Cem. Concr. Res. 2014, 58, 143-151. [CrossRef]

34. Luo, D.M.; Niu, D.T. Influences of water-to-cement ratio and curing condition on water absorption of internal curing concrete. J. Build. Eng. 2019, 40, 165-173.

35. GB/T 50081(2002); Standard for Test Methods of Mechanical Performance on Ordinary Concrete. Ministry of Housing and Urban-Rural Development of the People's Republic of China: Beijing, China, 2002; pp. 15-16.

36. Huang, H.F.; An, M.Z.; Wang, Y.; Yu, Z.R.; Ji, W.Y. Effect of environmental thermal fatigue on concrete performance based on mesostructural and microstructural analyses. Constr. Build. Mater. 2019, 207, 450-462. [CrossRef]

37. Zhang, X.; Bian, W. Study on the effect of aggregate composition on the water absorption characteristics of concrete. Technol. Highw. Transp. 2019, 15, 40-42+62. 
38. Cheng, B.J. Experimental Study on the Influence of Curing Conditions on Capillary Absorption of Concrete. Master's Thesis, Dalian University of Technology, Dalian, China, 2016.

39. Wang, L.C.; LI, M.Y. Influence of Short-Term Sustained Compressive Loading on Capillary Water Absorption of High Strength Concrete. J. Build. Eng. 2020, 23, 529-536.

40. He, Z.M.; Long, G.C.; Xie, Y.J.; Liu, J.Z. Water Sorptivity of Steam Curing Concrete. J. Build. Eng. 2012, 15, 191-194. [CrossRef]

41. Bao, J.W.; Hu, W.W.; Zhang, P.; Li, Z.; Lei, F.H.; Zhao, T.J. Effect of Organic Silicon Hydrophobic Agent on Strength and Capillary Absorption of Concrete. J. Am. Ceram. Soc. 2020, 48, 1644-1652.

42. Wei, L.L.; He, Z.M.; Li, Y.M.; Wang, J.M. Influence of mineral admixtures on transportation properties and pore structure of steam-cured concrete. J. Water Resour. And. Water Eng. 2020, 31, 179-186.

43. Xiao, Q.H.; Liu, X.L.; Qiu, J.S.; Li, Y.Y. Capillary Water Absorption Characteristics of Recycled Concrete in Freeze-Thaw Environment. Adv. Mater. Sci. Eng. 2020, 4, 1-12. [CrossRef]

44. Li, H.M.; Pan, Z.H.; Chen, Y.Y.; Yu, M.M. Research on the factors influencing water transport in cement-based materials. Concrete 2015, 9, 97-100.

45. Jiang, J.H.; Wu, Q.; Fu, Y.Q.; Lin, M.Y.; Sui, Y. Research on Moisture Absorption Process and Prediction Model of Recycled Concrete Mixed with Fly Ash. J. Build. Eng. 2021, 2, 1-12.

46. Ling, C.B. Experimental Study on Electrical Properties of Cement-Based Materials. Master's Thesis, Southwest Jiaotong University, Chengdu, China, 2020.

47. Liu, W.; Xing, F.; Xie, Y.J. Influence of mineral admixture on the water sorptivity of concrete. J. Shenzhen Univ. Sci. Eng. 2008, 25, 303-307.

48. Sun, J.Y. Research on Moisture Transport under Wetting and Drying Conditions. Master's Thesis, Zhejiang University, Hangzhou, China, 2012.

49. Ding, S. Research on the Relationship between Microstructure and Macroscopic Performance of Shotcrete. Master's Thesis, Xi'an University of Architecture and Technology, Xi'an, China, 2014.

50. Yang, H.M. Anti-freezing Material Used in RCC in Extremely Cold and High Altitude Areas and Its Action Mechanism. Ph.D Thesis, WuHan University, Wuhan, China, 2015.

51. Ma, Z.M.; Zhao, T.J.; Wang, P.G.; Wang, B.Z. Study on concrete capillary absorption effect mix with mineral admixtures. Concrete 2014, 3, 87-89.

52. Mohammed, T.U.; Hamada, H.; Yamaji, T. Concrete after 30 years of exposure-Part 1: Mineralogy, microstructures, and interfaces ACI. Mater. J. 2004, 101, 3-12.

53. He, F.Q.; Yuan, Q.; Zheng, K.R.; Liu, Y.H.; Zou, Q.Y. Correlations of test parameters of concrete with mineral admixtures according to ASTM C1202. J. Southeast Univ. (Nat. Sci. Ed.) 2006, S2, 105-109.

54. Deboucha, W.; Oudjit, M.O.; Bouzid, A.; Belagraa, L. Effect of Incorporating Blast Furnace Slag and Natural Pozzolana on Compressive Strength and Capillary Water Absorption of Concrete. Procedia Eng. 2015, 108, 254-261. [CrossRef]

55. Chang, H.L.; Jin, Z.Q.; Zhao, T.J.; Wang, B.Z.; Li, Z.; Liu, J. Capillary suction induced water absorption and chloride transport in non-saturated concrete: The influence of humidity, mineral admixtures and sulfate ions. Constr. Build. Mater. 2020, $236,117581$.

56. Li, M.Y. Experimental Study on Mass Transport in High Strength Concrete (HSC) with Blast Furnace Slag under Short-Term Sustained Compressive Loading. Master's Thesis, Dalian University of Technology, Dalian, China, 2019.

57. Gerard, B.; Breysse, D.; Ammouche, A.; Houdusse, A.; Didry, O. Cracking and Permeability of Concrete Under Tension. Mater. Struct. 1996, 29, 141-151. [CrossRef]

58. Wang, K.J.; Jansan, D.C.; Shah, S.P. Permeability Study of Cracked Concrete. Cem. Concr. Res. 1997, 27, 381-393. [CrossRef]

59. Zhang, P.; Wittmann, F.H.; Lehmann, E. Observation of water penetration in to water repellent and cracked cament-based materials by means of neutron radio graphy. Restor. Build. Monum. 2009, 15, 91-100. [CrossRef]

60. Niu, L.L.; Zhang, S.P.; Ge, C.Y. Influence of Steel Fiber on Capillary Water Absorption of Concrete under Load. Bull. China Ceram. Soc. 2018, 37, 2201-2205.

61. Lu, W.P.; Zhao, T.J.; Ma, Z.M.; Guo, A. Influence of Damage Load on the Capillary Absorption of the Concrete. Bull. China Ceram. Soc. 2015, 34, 50-54.

62. Bao, J.W.; Wang, L.C. Effect of Short-Term Sustained Uniaxial Loadings on Water Absorption of Concrete. J. Mater. Civ. Eng. 2017, 29, 04016234. [CrossRef]

63. Chen, B.L. Experimental Research and Mesoscale Numerical Simulation of Mass Transport Properties of Concrete under Shortterm Sustained High Compressive Stress. Master's Thesis, Dalian University of Technology, Dalian, China, 2020.

64. Tian, L.; Zhang, H.Y.; Zhao, T.J.; Shen, D.L. Research on permeability of strain hardening cement-based composites (SHCC) under compressive load. J. Build. Eng. 2009, 30, 328-332.

65. Dai, Z.Z. Study on the Coupling Effect of Uniaxial Continuous Load and Freeze-Thaw Cycles on the Durability of Concrete. Master's Thesis, Qingdao University of Technology, Qingdao, China, 2018.

66. Li, X. Porosity testing of cementitious materials based on electrical method. Low Temp. Archit. Technol. 2016, 38, 19-22.

67. Yang, L.; Gao, D.Y.; Zhang, Y.S.; Tang, J.Y.; Li, Y. Relationship between sorptivity and capillary coefficient for water absorption of cement-based materials: Theory analysis and experiment. R. Soc. Open Sci. 2019, 6, 190112. [CrossRef]

68. Wu, Z.W. Discussion on the recent development direction of concrete science and technology. J. Am. Ceram. Soc. 1979, 3, 262-270.

69. Shen, A.Q. Cement and Cement Concrete, 1st ed.; China Communications Press: Beijing, China, 2000; p. 93. 
70. Zhao, T.J. Concrete Permeability, 1st ed.; Science Press: Beijing, China, 2006; pp. 29-31.

71. Yin, H.Y. Study the Fractal Characteristic of Concrete's Pore Structure. Master's Thesis, Guangxi University, Nanning, China, 2006.

72. Li, Y.X.; Chen, Y.M.; He, X.Y.; Wei, J.X.; Zhang, W.S.; Zhang, H.T.; Guo, S.H. Pore volume fractal dimension of fly ash-cement paste and its relationship between the pore structure and strength. J. Chin. Chem. Soc. 2003, 31, 774-779. 